\title{
Modernização econômica e portuária: o caso do porto de São Sebastião (SP)
}

Moacir José dos Santos ${ }^{1}$

Edson Wagner Rodrigues ${ }^{2}$

\section{Resumo}

Os portos desempenham um papel importante por articular a produção e o consumo mediante a vinculação das diferentes esferas da cadeia produtiva, da produção ao consumo. Os portos constituem fator de indução do desenvolvimento local e regional, por atrair investimentos privados e públicos, como é o caso do porto de São Sebastião, que desempenha papel central na trajetória do município. Esse contexto subsidia o objetivo da pesquisa: delinear como ocorreu a transição histórica do porto natural ao porto organizado. Os dados foram obtidos a partir de uma pesquisa documental para a coleta de dados em documentos primários, com o propósito de se estabelecer a relação entre as atividades econômicas e a transição histórica do porto natural ao porto organizado. Os resultados demonstram a preponderância das características naturais para os investimentos realizados no porto organizado, com destaque para a instalação da Petrobras, na década de 1960. Conclui-se que a transição histórica do porto natural para o porto organizado decorreu do processo de modernização nacional e das exigências necessárias à ampliação da estrutura portuária do Brasil.

Palavras-chave: Modernização econômica. Estrutura portuária. São Sebastião.

\begin{abstract}
The ports play an important role in articulating the production and consumption by linking the different levels of the production chain, from production to consumption. Ports are factors of local and regional development by attracting private and public investment, as is the case of the port of São Sebastião, which plays a central role in the city's history. This context subsidizes the research objective: to outline how was the historical transition from the natural harbor to an organized port. Data was obtained from a documentary research, with data to collected on primary documents for the purpose of establishing the relationship between economic activities and the historical transition from the natural harbor to the organized port. The results demonstrate the preponderance of natural features to the investments made in the organized port, highlighting the Petrobras facility in the 1960s. We concluded that the

${ }^{1}$ Professor do Programa de Pós-Graduação em Planejamento e Desenvolvimento Regional (Unitau).professormoacirsantos@gmail.com

${ }^{2}$ Graduado em Gestão Empresarial. Mestre em Gestão e Desenvolvimento Regional (Unitau). Professor do Etec São Sebastião. ewrodrigues@gmail.com
\end{abstract}


historical transition from natural haven for an organized port held the national modernization and necessary prerequisites for expansion of port infrastructure in Brazil.

Keywords: Economic modernization. Port infrastructure. São Sebastião.

\section{Introdução}

No senso comum, os portos são tradicionalmente vistos e reconhecidos apenas como uma interface entre os transportes terrestres e marítimos. $\mathrm{O}$ crescimento do comércio mundial e a redução das barreiras comerciais aproximaram as empresas aos novos mercados e exigiram dos portos uma readequação funcional e espacial das suas funções, o que implicou a modernização portuária.

Observa-se, a partir desse contexto, a constituição de conhecimento consistente sobre as atividades portuárias e seus desdobramentos em razão da centralidade dos portos no comércio internacional. Entre os autores envolvidos no debate sobre o papel dos portos na perspectiva de negócios, está Christopher (2007). O autor ressalta a necessidade de uma estratégia logística global para orientar a administração e o funcionamento dos portos. O cerne desta estratégia é adequar o escoamento da produção em poucos locais e centralizar os estoques em Regional Distribution Centers (RDC) com maior alcance geográfico. Esse modelo exige um novo formato portuário, com a integração dos portos à cadeia global de abastecimento. Daí a premência de se modernizá-los, preparando-os para as condições produzidas com o deslocamento espacial mais intenso do capital (HARVEY, 2006).

Notteboom e Rodrigue (2005) destacam o papel funcional dos portos na cadeia de valor e a tendência da integração logística no setor portuário. Com essa formatação do sistema mundial portuário, novas demandas são colocadas aos portos e, consequentemente, às cidades que os abrigam. Nessa relação, os portos passam a ser um driver impulsionador e fator relevante para o desenvolvimento local (MONIÉ; VIDAL, 2006). A renovação das atividades portuárias, associada à dinâmica da circulação e reprodução contemporânea do capital, afeta a configuração dos portos brasileiros, relacionados às mudanças socioeconômicas derivadas da mobilidade de pessoas e cargas, aceleradas com a intensificação dos desdobramentos do comércio e transportes internacionais. O modal de transporte marítimo foi responsável por movimentar 969 milhões de toneladas em 2014, com incremento relativo de 4,25\% em relação a 2013. É o principal modal utilizado no comércio internacional (ANTAQ, 2015).

Novas demandas são atribuídas aos portos para adequá-los à crescente integração dos mercados internacionais, tornando-se necessária uma releitura de suas atribuições funcionais. No Brasil, iniciou-se um processo de modernização do setor portuário com a promulgação da Lei no 8.630/1993, que ficou conhecida como a Lei dos Portos (BRASIL, 1993). Em junho de 2013, foi promulgada a Lei no 12.815 , estabelecendo um novo marco regulatório para o setor na exploração de portos organizados e instalações portuárias, cujo propósito é equipar, modernizar os portos brasileiros e 
torná-los competitivos para a oportunidade crescente de mobilidade de pessoas e cargas (BRASIL, 2013).

O porto de São Sebastião "[...] tem uma configuração natural que o coloca como a terceira melhor região portuária do mundo" (CDSS, 2013, p. 8). A instalação do porto no período colonial decorreu das condições naturais presentes na localidade. Essa escolha caracterizou a origem e a história do município. Esse contexto define o objetivo deste trabalho: delinear como ocorreu a transição histórica do porto natural ao porto organizado. As atividades portuárias definiram a história do município. A presença das condições físicas, apropriadas ao funcionamento do porto, refletiramse na inserção histórica e econômica de São Sebastião no litoral norte paulista e na história brasileira. O artigo é composto por esta introdução e mais quatro seções. $\mathrm{Na}$ segunda seção, aborda-se a correlação entre o processo de modernização portuária e a ocupação do espaço, enquanto a terceira é dedicada à caracterização do processo histórico pertinente à passagem do porto natural para o porto organizado. A quarta seção apresenta as características que delineiam o atual porto de São Sebastião. E a última apresenta as considerações finais acerca da transição do porto natural para o porto organizado em São Sebastião.

\section{Modernização portuária e ocupação do espaço}

As funções e o impacto das atividades portuárias correspondem ao processo de ocupação e adequação do espaço sob a dinâmica das atividades econômicas historicamente constituídas. Sob essa perspectiva, Harvey (2006) busca entender os processos urbanos pertinentes ao capitalismo e seus efeitos sobre o espaço, que, nesse sentido, é organizado e utilizado como veículo e instrumento do capital. Tal perspectiva encontra ressonância no conceito de espaço geográfico de Santos (2006), concebido como produto de um processo de interação e de relação ativa estabelecida entre a sociedade e a natureza. O homem produz o espaço, o que é, nesse sentido, uma ação antrópica de interferência na natureza. Para Harvey (2006), há uma divisão tripartite no modo como o espaço pode ser entendido, e, dependendo das circunstâncias, pode se transformar em espaço absoluto, relativo ou relacional, "[...] o problema da concepção correta do espaço é resolvido pela prática humana em relação a ele" (HARVEY, 2006, p. 6).

Exemplo das concepções de Harvey é a dinâmica do comércio internacional, que aproximou as empresas transnacionais e suas estruturas produtivas (espaço) aos novos mercados, propiciando aos portos o meio de ampliar o fluxo mercantil internacional. De acordo com Santos (2009), essa inserção capitalista reorganiza o espaço com a reprodução das relações econômicas e sociais, favorecendo as distorções locais quanto à apropriação dos recursos produzidos.

Entretanto, faz-se necessário observar que a organização do espaço conforme a dinâmica de deslocamento do capital inclui o tempo necessário à sua transformação. O território é transformado mediante as ações realizadas no tempo e no espaço. Destarte, a passagem do porto natural ao porto organizado relaciona-se às mudanças decorrentes da inserção brasileira na divisão internacional do trabalho. 
No período colonial, a América portuguesa caracterizava-se por produzir os recursos necessários à manutenção da metrópole mediante a exploração dos recursos presentes na colônia. A formação do porto de São Sebastião remete a essa conjuntura histórica. No século XX, a industrialização brasileira e as condições necessárias ao crescimento econômico implicaram a ampliação da infraestrutura nacional, inclusive a portuária, com reflexos sobre o porto de São Sebastião.

A inserção brasileira na divisão internacional do trabalho, no século $X X$, ocorreu com investimentos estatais em infraestrutura para suportar a instalação de empresas transnacionais. A implantação do porto organizado em São Sebastião decorre da busca por dotar o país com condições mais adequadas àquela conjuntura histórica. Daí a presença do porto como fator de crescimento econômico e assimetrias sociais decorrentes desse processo em São Sebastião. Durante o século XX, desde a década de 1930, efetivaram-se medidas para modernizar o porto de São Sebastião e torná-lo uma das estruturas aptas a respaldar a industrialização brasileira e sua inserção internacional, especialmente com a presença de empresas transnacionais.

À medida que as empresas transnacionais se articulam espacialmente com suas estruturas produtivas, estabelece-se um processo de desequilíbrio nas relações econômicas e sociais, uma vez que existem forças desproporcionais com interferência no orçamento público. Sua articulação interfere na ocupação do espaço com impactos (desvantagens) que são socializados. Singer (1975) reforça que, embora as desvantagens sejam causadas pelas empresas, os custos para a solução dos problemas (desvantagens) são socializados, pois cabe ao poder público as ações para dirimir os conflitos sociais e econômicos. Exemplos podem ser notados nas cidades portuárias, com aumento da ocupação da malha viária urbana quanto ao uso intenso de veículos pesados para acesso ao porto, com intervenção pública nos investimentos para melhoria da mobilidade urbana. Para a recuperação e melhoria da infraestrutura e acesso portuários, a Secretaria Especial de Portos estabeleceu um Plano Nacional de Logística Portuária (PNLP), com investimentos de $\mathrm{R} \$ 54,6$ bilhões, para melhorar o desempenho dos portos (SEP/PR, 2012). Há, no entanto, reflexos nas cidades em que esses portos estão inseridos, que nem sempre se traduzem em oportunidades sociais (RODRIGUES; SANTOS, 2014).

A cidade, com a integração vertical da produção das empresas transnacionais, atrai fluxos migratórios para atender ao interesse do capital de expansão dos seus negócios (SINGER, 1975). As demandas sociais que se instalam nas cidades são oriundas da concentração espacial, condição essencial para o desenvolvimento das empresas privadas e característica da economia capitalista. A concentração espacial do capital traz vantagens às empresas quanto à escala comercial produtiva. As desvantagens causadas pela aglomeração são socializadas, e os custos sociais transferidos ao poder público (SINGER, 1975). Segundo o autor, a cidade é o local em que a classe dominante expressa e maximiza a sua extração.

Nas cidades portuárias, há uma degradação socioambiental no entorno do porto, como miséria, prostituição, insegurança e poluição ambiental (MONIÉ; VIDAL, 2006; PORTO; TEIXEIRA, 2001). A área do entorno portuário, no Brasil, é um local que, historicamente, concentra a população de baixa renda, com bairros proletariza- 
dos e ocupação desordenada (KAPPEL et al., 2005). Singer (1975, p. 131) salienta que essa marginalidade urbana, "[...] produto do desenvolvimento capitalista, tem como objetivo um exército de reserva para expansão do capital". Porto e Teixeira (2001) e Kappel et al. (2005) atribuem a degradação no entorno portuário ao afastamento das autoridades municipais e portuárias das demandas da população local.

No Brasil, as políticas públicas portuárias carecem de maior consistência, e esse é o principal desafio na transformação e modernização dos portos para cumprirem seu papel no desenvolvimento local (MONIÉ; VIDAL, 2006). Nas recentes transformações das cidades portuárias, os autores atribuíram como tendência um parque portuário capaz de adicionar atividades terciárias para agregar valor ao fluxo de cargas internacionais que transitam pelos portos. Nesse contexto, é possível produzir oportunidades para o tecido produtivo local na montagem de inúmeros produtos que necessitam de uma adaptação regional para o consumo. A condição do porto de estabelecer sinergias com a comunidade local o transforma em potencial instrumento de desenvolvimento local.

O conceito de desenvolvimento, aplicado às características da cidade portuária, deve considerar as demandas socioambientais com enfrentamento adequado às questões históricas que permeiam o ambiente portuário, especialmente os graves problemas presentes no entorno do sítio portuário analisado no presente artigo. A cidade portuária deve ser vista sob o prisma da dimensão social do desenvolvimento, em que as questões socioambientais adquirem relevância em relação aos princípios do crescimento no conceito de desenvolvimento (SANTOS et al., 2012).

Cidades portuárias atraem massa migratória, especialmente nas etapas de grandes obras civis para instalação e construção da infraestrutura portuária. Após o término da construção, os trabalhadores permanecem na cidade, ocupando o território no entorno do porto, criando, como já argumentado, bairros proletarizados (RESSURREIÇÃO, 2002; CORRÊA DA SILVA, 1975). Quanto ao fluxo migratório, Cano (2007) ressalta que a urbanização, a instalação e a concentração das indústrias em grandes cidades foram as forças atrativas para a massa migratória que, impulsionada por crises sociais, compôs o êxodo rural no Brasil. Para o autor, o fenômeno da urbanização, mesmo que periférica, é "[...] geratriz de novas demandas de bens e serviços simples, germinadores por sua vez, de novas ocupações" (CANO, 2007, p. 126).

De 1956 a 1962, o desenvolvimentismo de Juscelino Kubitscheck atraiu, principalmente para o eixo Rio-SP, um fluxo migratório seduzido por possibilidades de emprego e renda. Após o período conhecido como o milagre brasileiro, no início da década de 1970, houve uma desaceleração do crescimento, e, em 1975, instalou-se uma nova crise social com elevada saída de pessoas do Nordeste. Cerca de 2,3 milhões de pessoas deixaram a região. O censo de 1980 aponta 16,5 milhões de migrantes nacionais (IBGE, 2013). São Paulo recebeu cerca de 6 milhões de migrantes, principalmente nordestinos e mineiros. O desequilíbrio regional resultante desse contexto histórico foi aprofundado com as políticas econômicas neoliberais mediante a abertura, a desregulamentação e a privatização que se sucederam na década de 1990, responsáveis por promover a concentração da riqueza e da renda, ampliando a miséria social (POCHMANN, 2015). 
Ressurreição (2002, p. 213) descreve o movimento migratório no período de instalação do Terminal de Uso Privado (TUP) da Petrobras, em São Sebastião, com a chegada de trabalhadores mineiros e nordestinos ao município: "[...] caminhões e mais caminhões de empreiteiras chegavam à cidade carregados de homens mineiros das cidades de Boa Esperança, Teófilo Otoni, Almenara, para trabalhar como serventes, pedreiros, amadores". Esses trabalhadores atuaram na construção das instalações da Petrobras. Promoveram, então, um movimento de ocupação e aglomeração nas proximidades do Porto Organizado. Com o término do contrato das empreiteiras com a Petrobras, muitos desses trabalhadores permaneceram em São Sebastião com seus familiares, ocupando áreas precárias de urbanização. Estabeleceram-se, então, os bairros proletarizados (RESSURREIÇÃO, 2002). O fenômeno de ocupação desordenada no entorno portuário, com grande concentração de população de baixa renda, é histórico e recorrente nos portos brasileiros (MONIÉ; VIDAL, 2006; PORTO; TEIXEIRA, 2001; KAPPEL et al., 2005).

\section{Do porto natural ao porto organizado}

São Sebastião, cidade balneária do litoral paulista, ligada à Sub-Região 5 Litoral Norte, integra a Região Metropolitana do Vale do Paraíba e Litoral Norte (RMVALE), conforme a Figura 1. É a cidade mais antiga do litoral Norte. Sua ocupação ocorreu desde o século XVI, emancipando-se politicamente em 1636. São Sebastião participou dos ciclos econômicos do açúcar, do café e do extrativismo do ouro, em Minas Gerais, mediante a utilização do porto. Suas características naturais facilitavam a navegação e a segurança na ancoragem pelas águas abrigadas do canal de São Sebastião.

Documentos históricos primários ratificam o porto como decisivo para a formação da cidade no âmbito da colonização portuguesa (CO 1284 de 07/11/1877, AESP). O canal de São Sebastião e o porto natural tornaram-se, desde o século XVI, os principais ativos para a origem colonial do município. A relação mar e porto constitui a principal via de movimentação econômica de São Sebastião. O município destacase por ter um porto organizado, de relevância nacional, que abriga o porto público e o Terminal Marítimo Almirante Barroso da Petrobras (TEBAR).

O acesso rodoviário ao porto se dá unicamente pela zona urbana de São Sebastião, que é transpassada pelas rodovias SP-055/BR-101 e Manoel Hypólito do Rego, que faz a ligação Rio-Santos (Figura 2). Toda a produção movimentada pelo porto tem como gargalo a interligação com essa única via de acesso à zona urbana de São Sebastião, por meio das avenidas São Sebastião e Avenida Dr. Altino Arantes. Há uma sobreposição dos tráfegos urbano e regional dos veículos, em deslocamento intercidades, com a utilização da SP-055 e a Rio-Santos. 
Figura 1 - Localização de São Sebastião

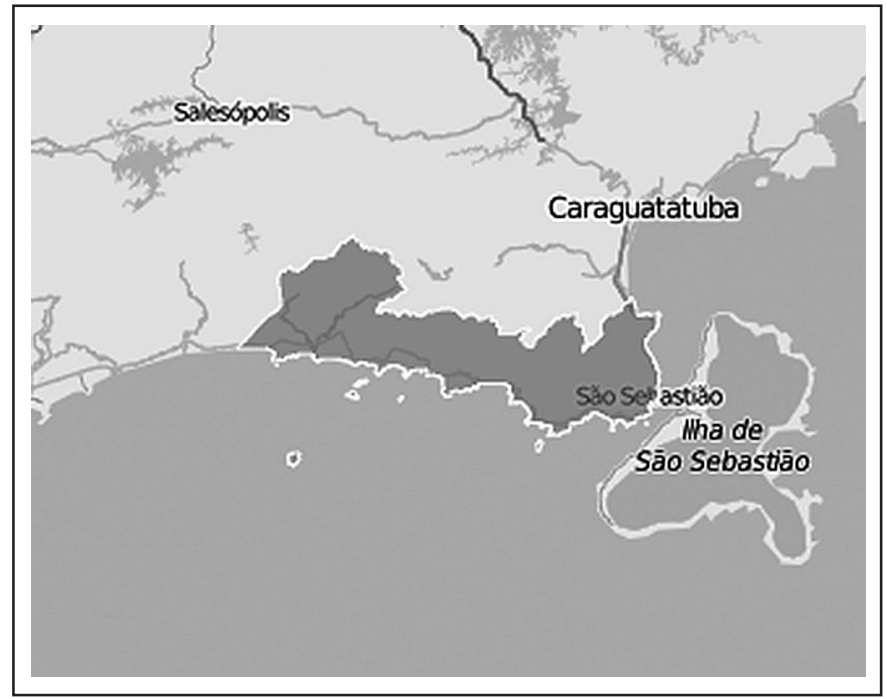

Fonte: IBGE (2016).

Figura 2 - Acesso Urbano ao Porto

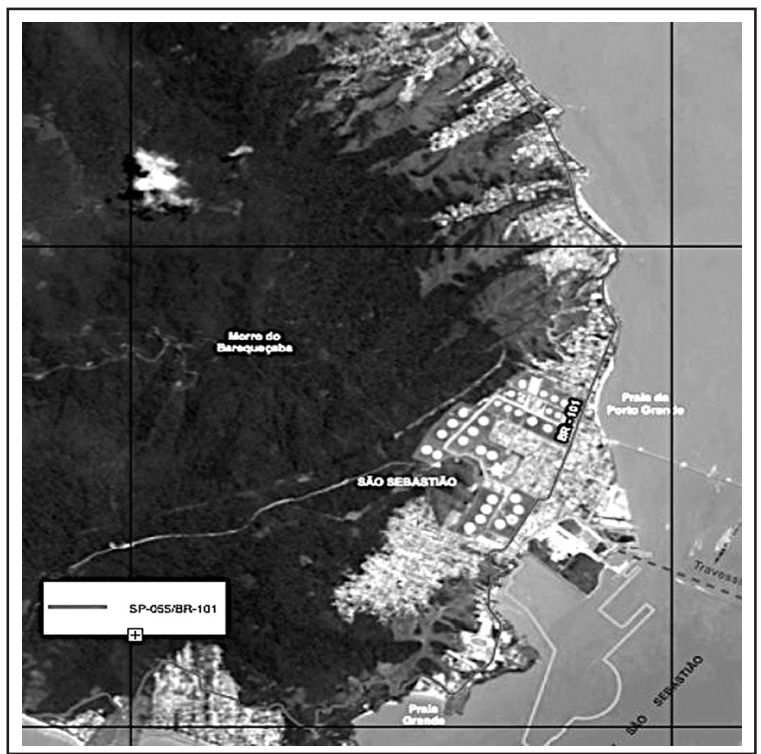

Fonte: CDSS (2014). 
A zona de influência do porto de São Sebastião se dá pelo conjunto de rodovias que interligam as regiões metropolitanas de São Paulo, Campinas, Rio de Janeiro, sul de Minas e Vale do Paraíba. O acesso ao Vale do Paraíba se dá pela SP-099, Rodovia dos Tamoios, que faz sua interligação com a SP-055/BR-101, em Caraguatatuba. Está em execução o projeto do governo do estado de São Paulo, que interliga a Rodovia dos Tamoios ao porto por uma alça, retirando, assim, o tráfego de veículos pesados da malha urbana. A BR-116, Rodovia Presidente Dutra, que faz a ligação São Paulo - Rio, tem sua intersecção na Rodovia dos Tamoios. A região metropolitana de Campinas é interligada pela SP-065, Rodovia Dom Pedro I (Jacareí-Campinas), e pelo sistema Ayrton Senna - Carvalho Pinto, que liga São Paulo a Taubaté e faz também intersecção com a Rodovia dos Tamoios.

Na área do porto organizado de São Sebastião, encontram-se o Porto Público e o Terminal Marítimo Almirante Barroso (TEBAR), da Petrobras. O Porto Público compreende um píer em forma de "L", em concreto, apoiado em tubulões. O cais é formado por quatro berços de atracação. O berço externo, frontal ao canal de São Sebastião (berço 101), tem uma profundidade que permite operação de navios com $8 \mathrm{~m}$ de calado; dispõe de 150 m de cais e mais três dolfins que somam 125 m, destinados a auxiliar a amarração do navio, sendo dotado de condições para receber navios de cabotagem ou longo curso. Quanto à extensão, o berço 201 tem 50 m; o 202 tem 75 m; e o 203 tem 85 m. Esses berços, com 7,0 m de profundidade, atendem a pequenas embarcações. A Portaria-MT 400, de 15/07/1994, define e constitui a área do porto organizado de São Sebastião.

As instalações de armazenagem são compostas por cinco recintos alfandega-

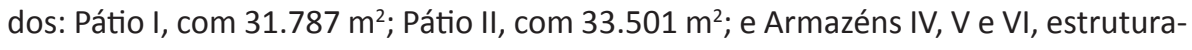
dos com $2.000 \mathrm{~m}^{2}$ cada, e instalados em pátio de $31.725 \mathrm{~m}^{2}$. O Pátio I é descoberto e destinado à carga geral, contêineres, máquinas e equipamentos. O Pátio II, também descoberto, destina-se preferencialmente a veículos que são embarcados e desembarcados. A área total dos dois pátios é de $65.288 \mathrm{~m}^{2}$, totalmente pavimentada e cercada com gradil. O porto possui ainda área não alfandegada, composta pelos Pátio III, de aproximadamente $120.000 \mathrm{~m}^{2}$, com revestimento primário compactado; Pátio IV, de aproximadamente $12.000 \mathrm{~m}^{2}$, com revestimento primário compactado, e $130.000 \mathrm{~m}^{2}$ em aterro hidráulico destinado à expansão. Esse pátio não alfandegado, com área de $142 \mathrm{mil} \mathrm{m}^{2}$, é utilizado atualmente para deposição do material dragado da manutenção da areia e do berço 101 externo.

A área do Porto Público de São Sebastião abriga o núcleo de polícia marítima da Polícia Federal; o posto fiscal da Receita Federal; a sala dos sindicatos; balança; guaritas; escritórios; vestiários e banheiros (CDSS, 2014). Os acessos aquaviários do canal de São Sebastião ao Porto constam das Cartas Náuticas DHN no 1614, 1643 e 1644. O canal tem 12,3 milhas de extensão e, na sua parte sul, permite o acesso de navios com calado de 23 metros. A parte norte do canal permite a entrada e a saída de navios com calado de 10 metros (CDSS, 2014). O porto possui também dois fundeadouros previstos na Carta Náutica DHN 1614: o primeiro, na Barra Norte, destinado a navios com mais de 100.000 TPB (toneladas de porte bruto), e o fundeadouro da Barra Sul, com capacidade para quatro navios. 
A constituição e operação do porto de São Sebastião é resultado da transição entre o aproveitamento das condições naturais facilitadoras da realização das atividades portuárias e as intervenções realizadas para aprimorar sua utilização comercial. O denominado porto natural corresponde à simultaneidade entre o início da ocupação do espaço em que se situa o município de São Sebastião e a comunicação com outras áreas do litoral da América portuguesa e também com a própria metrópole no período colonial. A transição de um porto natural a um porto organizado comercial até a sua conformação contemporânea, com suas características, denota a trajetória de exploração desta vantagem natural, possibilitada com a inserção econômica de São Sebastião no processo de colonização. Note-se, o porto foi o vetor da trajetória histórica de São Sebastião, consolidando-se como elemento decisivo para as mudanças presentes no município desde o período colonial.

A origem do porto natural é vinculada à facilidade de navegação e segurança na ancoragem e nas águas abrigadas do canal de São Sebastião, condições favoráveis para sua utilização e instalação da economia extrativista colonial (CORRÊA DA SILVA, 1975). Ao final do século XVI, a exploração colonizadora deu origem às primeiras feitorias e ações de povoamento. Os núcleos sociais se estabeleceram voltados para a frente do mar, com ruas que acompanhavam o desenho em forma de arco, com relativo afastamento da orla, representados pela Figura 3.

\section{Figura 3 - Villa de São Sebastião - Detalhe da Carta Corographica que mostra a configuração da Costa desde a ponta do Araçá de João da Costa Ferreira de 1815}

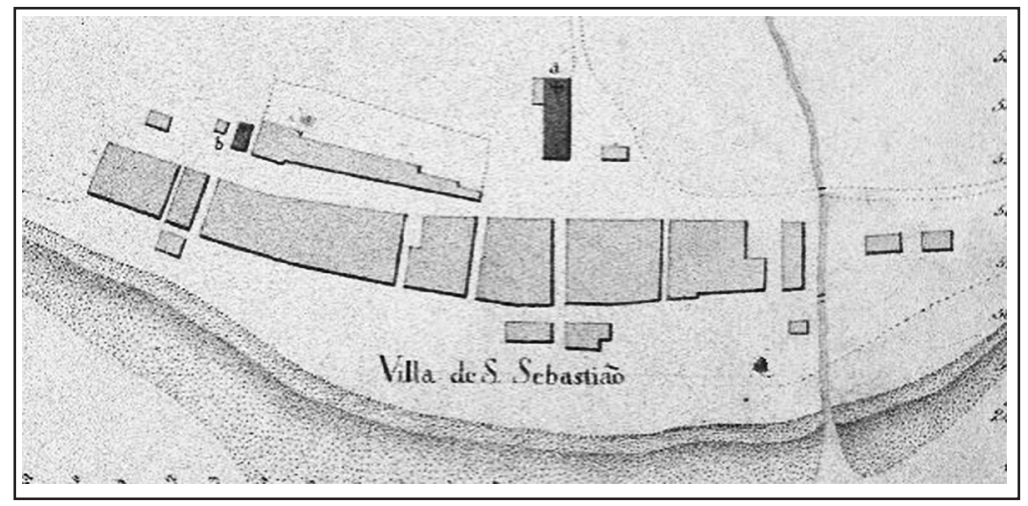

Fonte: Gianesella (2012, p. 190).

A Vila de São Sebastião foi um núcleo econômico relevante na capitania de São Paulo, no século XVIII, em razão da produção açucareira, consolidando uma agricultura dedicada à exportação. Em 1798, "[...] a vila atingiu seu pico na produção de açúcar" (RESSURREIÇÃO, 2002, p. 80), que foi escoada pelo porto natural, dirigindose principalmente à cidade do Rio de Janeiro, em busca de melhores preços. O governador Bernardo José de Lorena, pelo Decreto de 28 de dezembro de $1789^{3}$, proibiu o

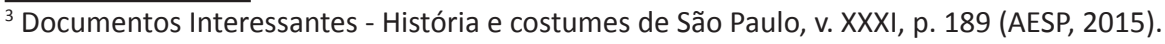


comércio dos portos da capitania de São Paulo com o Rio de Janeiro e estabeleceu o comércio somente com o porto da praça e vila de Santos. O decreto objetivava garantir o comércio direto com Portugal por meio do porto de Santos. A concentração das exportações nesse Porto trouxe decadência e desespero aos exportadores da vila de São Sebastião (RESSURREIÇÃO, 2002). Almeida ressalta o impacto dessa medida que interrompeu o comércio entre as vilas:

Já nos tempos coloniais impunha-se a necessidade do intercâmbio comercial entre as vilas do litoral paulista e os portos da Capitania do Sul, do que resultou o desenvolvimento das construções navais na Capitania de São Paulo, onde se fundaram numerosos estaleiros, possuindo as mesmas vilas verdadeiras frotas mercantes que percorriam toda a costa e que pouco a pouco foram desaparecendo, depois daquela medida absurda imposta pelo Capitão General Bernardo José de Lorena, desviando as mercadorias para o porto de Santos (ALMEIDA, 1959, p. 19).

Uma pipa de aguardente, que era vendida no Rio de Janeiro por 50\$000, passou a ser comercializada no porto de Santos a 24\$000 (ALMEIDA, 1959), dado o pesado tributo, que detinha $21 \$ 000$ em subsídios, novos impostos e demais despesas de cada pipa, ficando com o exportador a quantia de $3 \$ 000$. Os preços praticados na vila de Santos, consequentes de uma formação oligopisônica, foram denunciados em 1798 para o então governador Antônio Manuel de Melo e Castro, em correspondência, com o objetivo final de restabelecer a economia local com a plena utilização do porto marítimo:

Fecharãce os portos a Navegação q. se fazia para o Rio de Janeiro como d.o fica, e as Embarcações, gente de comercio se auzentarãop.lo gravíssimo prejuízo que experimentavão na V.a de Santos; logo não ouve quem compraçe os efeitos, aos lavradores se não p.r hum tão diminuto preço que mal chegava p.a os Direitos, [...] Ficou esa Villa quzi comprara a hum deserto Certão, p.r aqui só vem p.racazo algum atrabesador auxiliado p.lo pred. to Q.I M.e. e estes deixao mais prejuízos aos lavradores do que lucro, p.a que lhe comprao os efeitos p.r m.to menos preço q. eles estão correndo nas mais p.es.

[...] De V. Ex.cia de cuja ilustre Grandeza nós esperamos ser remediados ficando assim estes abitantes mais animados, e capacitados q. não hão de ser constrangidos lever seus efeitos a V.a de Santos onde só tem meya dúzia de comerciantes q. para comprar qualquer efeito se mancunão huns com outros, afim de comprar os mesmos efeitos p.r menos valor, e por muito menos do q. estão correndo na Cid.e do Rio de Janeiro e outras... (AESP, 2015).

Em resposta aos vários questionamentos surgidos dos portos das vilas atingidas por essa medida, Antonio Joze da Franca e Horta ${ }^{4}$ afirmou que o receio de os negociantes de Santos não pagarem o preço justo da aguardente produzida era destituído de fundamento, pois tão logo os navios do reino chegassem ao porto de Santos, a concorrência dos compradores sustentaria o seu devido preço. Apesar da crise política e econômica decorrente da interferência da Província nos negócios da vila de

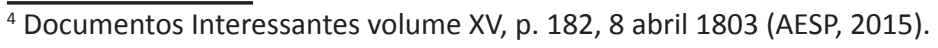


São Sebastião, o ciclo açucareiro produziu um incremento econômico potencializado pelo porto, que mantinha um importante papel no desenvolvimento e formação da cidade.

No ano de 1799, houve um reflexo monetário com a exportação de apenas $35 \$ 488$ mil réis em vários gêneros, com uma queda de $76,4 \%$ em relação ao ano anterior, reverberado pelo desespero dos produtores e exportadores locais nos diversos ofícios enviados à Província. Incrementaram-se, então, outras culturas para o consumo interno e exportação, como algodão, tabaco, feijão, farinha e azeite de baleia, este último utilizado como fonte de energia na iluminação das vilas.

\section{Tabela 1 - Mapa da Produção da Vila de São Sebastião dos anos 1798 e 1799}

\begin{tabular}{|c|c|c|c|c|c|c|c|c|}
\hline \multirow[t]{2}{*}{ Produtos } & \multirow[t]{2}{*}{ Medidas } & \multicolumn{2}{|c|}{ Produção } & \multicolumn{2}{|c|}{ Consumo } & \multicolumn{2}{|c|}{ Exportação } & \multirow{2}{*}{$\frac{\Delta \%}{\Delta \%}$} \\
\hline & & 1798 & 1799 & 1798 & 1799 & 1798 & 1799 & \\
\hline Algodão & Quintais & 0 & 131 & 0 & 131 & 0 & 0 & 0 \\
\hline Açucar & Quintais & 5.652 & 5.162 & 25 & 60 & 5.627 & 5.102 & $9,33 \%$ \\
\hline Tabaco & Quintais & 129 & 130,5 & 64 & 5,5 & 65 & 125 & $92,3 \%$ \\
\hline Arroz & Alqueire & 562 & 684 & 412 & 604 & 150 & 80 & $46,7 \%$ \\
\hline Goma & Quintais & 3 & 0 & 3 & 0 & - & 0 & 0 \\
\hline Anil & Quintais & 11,5 & 0 & - & 0 & 11,5 & 0 & $100 \%$ \\
\hline Café & Quintais & 6,5 & 9,5 & 6,5 & 1,5 & - & 8 & - \\
\hline Aguardente & Pipas & 237 & 207 & 11 & 25 & 226 & 182 & $19,5 \%$ \\
\hline Feijão & Quintais & 0 & 1.297 & 0 & 1.097 & 0 & 200 & - \\
\hline Milho & Alqueire & 196 & 220 & 196 & 220 & - & 0 & 0 \\
\hline Farinha & Alqueire & 26.804 & 25.478 & 26.380 & 23.428 & 424 & 2.050 & $383 \%$ \\
\hline T. Gêneros & \$ Réis & $192 \$ 414$ & $64 \$ 527$ & $41 \$ 936$ & $29 \$ 040$ & $150 \$ 476$ & $35 \$ 488$ & $76,4 \%$ \\
\hline $\begin{array}{l}\text { *Armação } \\
\text { Baleia }\end{array}$ & \$ Réis & $10 \$ 332$ & $19 \$ 942$ & $3 \$ 612$ & $3 \$ 402$ & $6 \$ 720$ & $16 \$ 630$ & $147 \%$ \\
\hline Total Geral & \$ Réis & $202 \$ 746$ & $84 \$ 469$ & $45 \$ 548$ & $32 \$ 442$ & $157 \$ 196$ & $52 \$ 778$ & $66,4 \%$ \\
\hline
\end{tabular}

*Os valores do contrato de Armação da Baleia são retratados ao final do Mapa Exportação Fonte: AESP(2015).

Quanto aos gastos monetários no ciclo açucareiro, Celso Furtado afirma que "[...] uma vez instalada a indústria, seu processo de expansão seguiu sempre as mesmas linhas: gastos monetários na importação de equipamentos, de alguns materiais de construção e de mão de obra escrava" (FURTADO, 2007, p. 84). Mesmo nos períodos prósperos na Vila de São Sebastião, a concentração da renda estava nas mãos dos donatários dos engenhos sem expressão monetária para a localidade, uma vez que não havia pagamentos a fatores de produção por se tratar de uma economia exportadora escravista. Daí a presença de práticas econômicas correspondentes ao arbítrio e à concentração de poder e renda nos sujeitos que controlavam a produção.

Esse modelo perdurou na transição para o contexto de predomínio das atividades ligadas à cafeicultura. Em meados do século XIX, o café apresentou participa- 
ção significativa na produção do litoral norte paulista, reproduzindo o ciclo de atividades instaladas em muncípios do Vale do Paraíba paulista, como Lorena, Silveiras, Piquete, Cruzeiro, Guaratinguetá e outras localidades, em seu conjunto, a maior área produtodora de café do Brasil. As atividades econômicas relacionadas à cafeeicultura no Vale do Paraíba e em São Sebastião promoveram um período de mudanças urbanas com a "[...] construção de prédios e abertura de ruas e praças" (ALMEIDA, 1959, p. 86). O porto desempenhou papel central no litoral norte paulista, na formação e organização social e econômica do espaço: "[...] havia o bem-estar máximo proporcionado pela época: residências de requintado luxo e conforto, grêmios literários, clubes e escolas" (ALMEIDA, 1959, p. 153).

São Sebastião, Ilhabela e Ubatuba produziram 84.134 arrobas de café em 1834 contra 33.649 arrobas da região de Lorena. Em 1854, a produção de café no litoral Norte foi de 296.000 arrobas em comparação a 125.000 arrobas da região de Lorena (CORRÊA DA SILVA, 1975). O cultivo do café e sua exportação pelo porto local trouxe, por um pequeno período, riqueza para São Sebastião (RESSUREIÇÃO, 2002). Em 1854, o município possuía 106 fazendas de café, produzindo 86.000 arrobas (ALMEIDA, 1959). O cultivo era abastecido pela mão de obra escrava, cuja média era de 5,1 escravos por propriedade (LUNA; COSTA, 1983). A ruptura do sistema escravista com diminuta mão de obra e a ocorrência de pragas nos cafezais fez com que as fazendas entrassem em declínio, o que pode ser observado em correspondência da Câmara Municipal de São Sebastião ao Presidente da Província Sr. Sebastião José Pereira ${ }^{5}$. 0 reflexo desse declínio foi o deslocamento do eixo econômico do litoral Norte para o Vale do Paraíba, que, com a crescente produção do café, recebeu parte do êxodo da população caiçara, com os seus escravos remanescentes, como demonstra a Tabela 2. Esse êxodo ocorreu também nas demais cidades do litoral Norte (ALMEIDA, 1959).

Tabela 2 - População Vale do Paraíba (1836-1854)

\begin{tabular}{lcccc}
\hline \multicolumn{1}{c}{ Municípios } & \multicolumn{2}{c}{ População Escrava } & \multicolumn{2}{c}{ População Total } \\
& 1836 & 1854 & 1836 & 1854 \\
\hline Bananal & 1.679 & 7.621 & 6.708 & 11.482 \\
Paraibuna & 1.522 & 1.964 & 3.169 & 7.261 \\
Pindamonhangaba & 524 & 5.628 & 7.915 & 14.636 \\
São Luiz Paraitinga & 1.458 & 2.392 & 6.296 & 10.393 \\
São José dos Campos & 458 & 928 & 3.909 & 6.935 \\
São Sebastião & 1.710 & 1.285 & 4.230 & 4.101 \\
\hline
\end{tabular}

Fonte: Adaptada de Ressurreição (2002, p. 182).

A expansão da cultura cafeeira no Brasil, ao final do século XIX, com a hegemonia na oferta mundial desse artigo de exportação, possibilitou a inversão em estradas de ferro, portos e meios de transporte marítimo (FURTADO, 2007). A produ-

${ }_{5}^{5}$ Ofícios da Secretaria de Governo CO 1284 (AESP, 2015). 
ção cafeeira do Vale do Paraíba passou a ser drenada para o porto do Rio de Janeiro, facilitada pela construção da ferrovia D. Pedro II, atual Central do Brasil, inaugurada em julho de 1877. A construção da São Paulo Railway, em 1867, trouxe ao porto de Santos a hegemonia como escoadouro da produção paulista (ALMEIDA, 1959). O interesse pelo porto de Santos, estabelecido por políticas públicas e investimentos em infraestruturas ferroviárias, serviu como bloqueio ao desenvolvimento do porto de São Sebastião (CUNHA, 2003; ALMEIDA, 1959; SÃO PAULO, 1953). O município e o litoral norte ficaram aquém da euforia produzida em todo o estado de São Paulo pelo café e da consequente urbanização.

Em 1892, o engenheiro Casemiro Mottet faz o primeiro projeto para transformar o porto natural em um porto comercial (REIS, 2011). O projeto não obteve apoio para sua implantação, e, em Santos, nesse mesmo ano, foi inaugurado o primeiro trecho de cais acostável e aparelhado no Brasil (SÃO PAULO, 1953). Esse episódio postergou a modernização do porto de São Sebastião, com a manutenção de uma capacidade de operação reduzida em comparação às exigências comerciais do final do século XIX e início do século XX.

A construção de ferrovias também provocou dificuldades de articulação entre o porto de São Sebastião e os centros de produção. No período de 1870-1900, houve uma aceleração dos projetos ferroviários na Europa e América do Norte, chegando a 800.000 km em rede ferroviária. Para as regiões periféricas, como África e América do Sul, o sistema ferroviário foi uma ferramenta de controle colonial e apropriação de recursos por potências europeias (RODRIGUE, 2013). Em São Sebastião, inúmeros projetos para construção de ferrovias não obtiveram êxito, como o projeto de extensão de ramais de ligação entre São Sebastião e Mogi das Cruzes. A Lei no 29 de 29 de junho de 1892 "decretou a construção de uma estrada de ferro do porto de S. Sebastião às raias do estado de Minas Geraes", e, no mesmo ano, foram executados estudos visando ligar o porto de São Sebastião a São Bento do Sapucaí, passando por São José dos Campos ou Taubaté.

O governo federal, atendendo a um requerimento da Companhia Paulista de Vias Férreas e Fluviais, autorizou, pelo Decreto no 983, de 8 de agosto de 1892, o prolongamento da sua estrada de Jundiaí até o ponto mais conveniente ao porto de São Sebastião. De acordo com a cláusula XIII desse decreto, poderia ser construída, dentro da área do porto de São Sebastião, “[...] uma ou mais pontes marítimas, para facilitar o serviço de descarga de materiaes para a sua estrada, podendo mais tarde utilisar-se das ditas pontes para o serviço de embarque e desembarque de quaesquer mercadorias" (BRASIL, 1892). Tanto o porto como as ferrovias previstas no projeto não foram desenvolvidos, reduzindo a participação de São Sebastião nas atividades portuárias e comerciais do país.

\section{0 porto organizado}

A análise histórica do porto natural evidenciou a contribuição do porto para a formação da Vila de São Sebastião, com reverberação dos impactos na formação contemporânea e no município. 
As limitações do porto de São Sebastião são relativas às mudanças relacionadas à decadência da produção cafeeira e à emergência de novos centros de produção e atividade portuária, especialmente o porto de Santos. Porém, a industrialização no século XX provocou a modernização do porto de São Sebastião. Em 1934, quando da outorga e concessão do porto ao estado de São Paulo, para construção e exploração, pelo Decreto Federal no 24.729, de 13/07/1934, inicia-se a transição para o porto organizado. Tratava-se da modernização da operação portuária com a superação do uso condicionado às características naturais do porto.

Na linha temporal dos eventos da Figura 4, caracterizam-se os principais acontecimentos da transição do porto natural ao porto organizado. O período anterior a 1934 foi incluído, em razão de uma autorização anterior para a modernização do porto de São Sebastião, decorrente da crise portuária de 1925 ter caducado em 1930, com a extinção da Comissão de Portos. A ênfase da cronologia dá-se entre os anos de 1936 e 1961, quando ocorreram as principais intervenções antrópicas, como a construção do porto comercial e a construção do TUP Tebar, respectivamente, que foram decisivas na intervenção e relação com a cidade.

\section{Figura 4 - Principais eventos do porto comercial de 1925 a 2008}

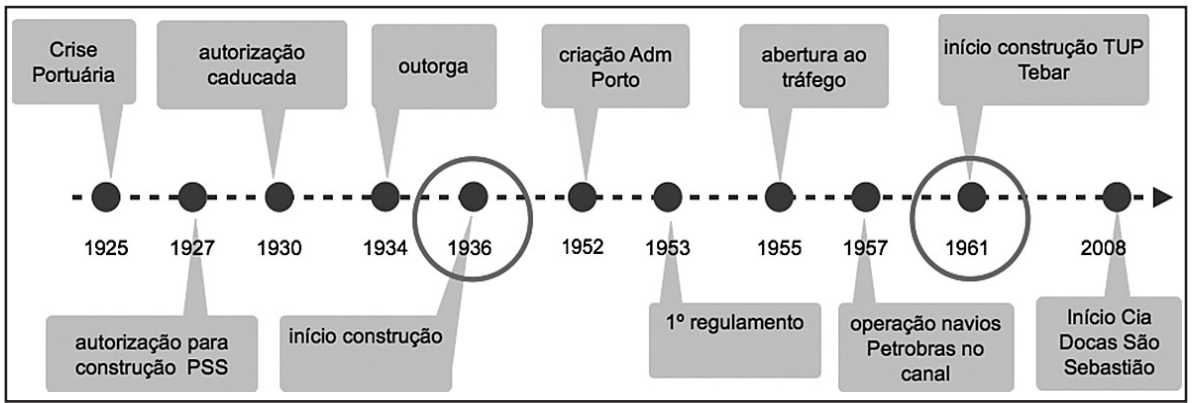

Fonte: Rodrigues (2015).

O ano de 1925 foi marcado por uma grave crise no sistema portuário brasileiro. No porto do Rio de Janeiro, a Cia. Brasileira de Exploração de Portos fez, a título precário, o alfandegamento de armazéns externos para ampliação do espaço destinado à conferência e armazenagem. Concomitantemente, foram tomadas outras medidas, como o reaparelhamento do porto com a eletrificação dos guindastes ainda movidos à mão e a construção imediata do prolongamento do porto, autorizada desde 1923 (DOU, 1925). Em Santos, o porto enfrentava o agravamento do congestionamento pelos mesmos problemas estruturais observados no do Rio de Janeiro.

Em 4 de maio de 1925, o Diário Oficial da União caracterizou a crise portuária santista: 
No segundo trimestre do anno findo, o movimento de entrada de mercadorias extrangeiras, no porto de Santos, que se vinha avolumando de modo a approximar-se do verificado em 1913, quando se registrára o maior coefficiente de aproveitamento do respectivo cáes, proseguia em ascenção constante e, não encontrando sufficientementeapparelhadas de material rodante as estradas de ferro em ligação com o porto, depressa a situação se aggravou, assumindo os característicos de congestão do grande emporio paulista (DOU, 1915, p. 81).

Para o enfrentamento da crise portuária de 1925, o governo federal propôs a instalação de silos para grãos, tanques para o granel líquido e a modernização do aparelhamento mecânico, para o carregamento de café, e a dragagem, para aumentar a profundidade a 10 m, de modo a permitir a atracação dos grandes vapores transoceânicos no cais, bem como a melhoria da malha ferroviária da São Paulo Railway. No contexto da crise portuária, o governo federal concedeu, em 1927, por intermédio do Decreto no 17.957/27, a autorização para a construção do porto em São Sebastião, que caducou em 1930, com a extinção da Comissão de Portos (SÃO PAULO, 1953). Essa autorização foi concretizada em 1934, protelada pelos acontecimentos políticos e militares de 1930 e 1932 (SINGER, 1975, p. 31).

Quando da instalação da Assembleia Nacional Constituinte, de 15 de novembro de 1933, Getúlio Vargas sinalizou a necessidade de tornar os portos acessíveis e com instalações adequadas:

Existem ancoradouros em alguns Estados totalmente desprovidos da mais rudimentar aparelhagem. Por eles, entretanto, se escoa a produção local e se faz intercâmbio com os demais centros comerciais espalhado ao longo do nosso vasto litoral. É de necessidade portanto, torná-los utilizáveis e accessíveis a navegação, dotando-os de recursos e instalações adequadas (BRASIL, 2015, p. 507).

O governo provisório de Getúlio Vargas regulamentou, pelo Decreto no 24.447, de 22 de junho de 1934, o porto organizado e as instalações portuárias no Brasil. Com o Decreto no 24.599, de 6 de julho de 1934, o governo federal outorgou a concessão aos estados em cujo território se encontravam os portos. Dessa forma, nos termos do Decreto no 23.820/34, em consonância com o Decreto no 24.599/34, foi concedida ao estado de São Paulo autorização para realizar obras e reaparelhamento do porto de São Sebastião, concedendo por 60 anos o direito de exploração, de 1934 a 1994, período prorrogado até 2007.

O projeto original de construção seguiu basicamente o do engenheiro Casemiro Mottet, de 1892, prevendo um aumento da área do porto em direção à praia do Araçá, de acordo com Figura 5 (inserida na próxima página). 0 assentamento do porto foi realizado por meio do enrocamento e aterro da área destinada ao acesso dos piers de atracação, dividindo a baía da Praia da Frente e Araçá. A configuração do cais e berços de atracação de hoje em São Sebastião é basicamente a mesma do projeto inicial, com pouca flexibilidade às mudanças necessárias, o que exige grande esforço e altíssimos investimentos para sua adequação. 


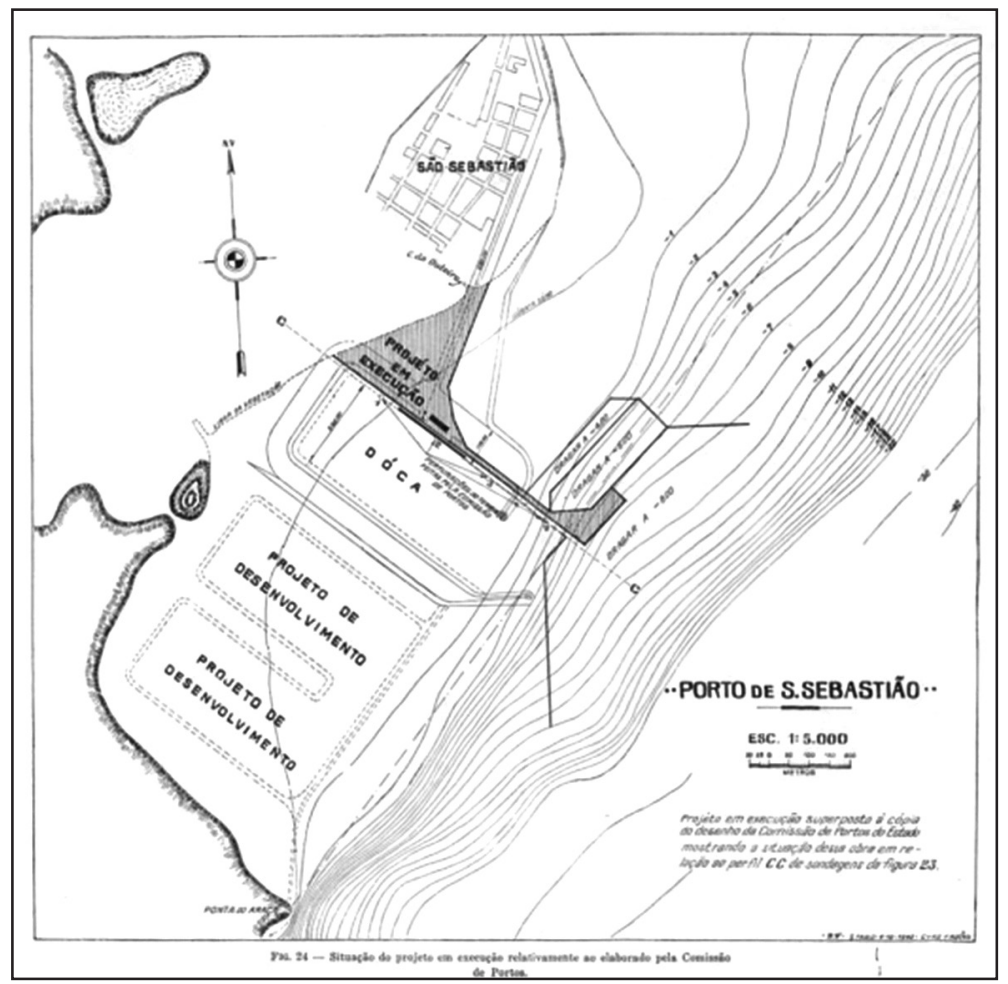

Fonte: São Paulo (1953).

O projeto foi executado pela Cia. Nacional de Construções Civis e Hidráulicas, empresa com experiência em obra portuária, como o prolongamento do cais do porto do Rio de Janeiro. A obra foi iniciada em 26 de abril de 1936, com orçamento aprovado de 4.853:292\$000 (SÃO PAULO, 1952). A construção se estendeu até 1942 e, em 1952, foi regulamentada com a criação da Administração do Porto de São Sebastião pela Lei no 1.776 de 18 de setembro de 1952 (SÃO PAULO, 1952) e aberta ao tráfego em 1955 (CDSS, 2014).

O primeiro regulamento do Porto estabeleceu as condições gerais que disciplinam a execução das operações portuárias na área do cais comercial público, editado e aprovado pelo Decreto no 22.518, de 17 de julho de 1953, na etapa final dos últimos ajustes da construção do Porto (SÃO PAULO, 1953).

A instalação da Petrobras no município, em 1960, foi vista com euforia pela população, pois representava a possibilidade de desenvolvimento econômico com oferta de empregos e renda. O Decreto no 50.555, de 5 de maio de 1961, em seu Art. 1으, autoriza a Petrobrás, na qualidade de detentora do monopólio do petróleo, instalar e operar no canal de São Sebastião um terminal marítimo de petróleo (BRASIL, 1961). Antes mesmo da sua instalação, desde 1957, a Petrobras utilizava o canal de São Sebastião para realizar o transbordo de petróleo dos navios grandes para navios 
pequenos que iriam, posteriormente, descarregar em Santos devido ao calado dos navios (FRANCISCO; CARVALHO, 2003). A segurança na operação pelas águas abrigadas e profundidade do canal foram os principais atributos que atraíram para São Sebastião a Petrobras, vencendo o lobby santista (CUNHA, 2003; CORRÊA DA SILVA, 1975).

O início da década de 1960 marcou a vida econômica e social local, com a inserção de atividades de petróleo e navegação, reflexo do governo de Juscelino Kubitschek, de 1956 a 1960, e dos novos mecanismos de ação estatal no setor produtivo, com investimentos em infraestrutura (navegação) e indústrias básicas (petróleo e aço) (RODRIGUES; SANTOS; OLIVEIRA, 1992). A instalação do Terminal Marítimo da Petrobrás promoveu um processo de intervenção espacial com a desapropriação de áreas para as suas instalações, impactando na mudança da relação da sociedade com a terra e profunda alteração da fisionomia da cidade. A empresa ocupou considerável área do centro da cidade. A intervenção continuou em 1971, com o Decreto no 69.143/71, que desapropriou uma área total de 678.200.81 $\mathrm{m}^{2}$. Pátios, dutos de produtos perigosos e grandes tanques de petróleo são instalados no centro urbano, avançando sobre áreas residenciais (RESSURREIÇÃO, 2002). A geração de emprego e renda e o aumento da circulação de divisas no município são contribuições diretas da atividade portuária. Atraem fluxos migratórios para atender à expansão dos negócios, como ocorreu no município em virtude das duas grandes obras civis realizadas: a construção do porto comercial e a construção do Terminal Marítimo da Petrobras, com os custos sociais transferidos ao poder público.

\section{Considerações finais}

A instalação do porto de São Sebastião, no período colonial, decorreu das condições naturais presentes na localidade. As condições naturais, naquele momento, constituíam os fatores mais relevantes para o escolha de um local para abrigar atividades portuárias. Tal escolha definiu a origem e a história do município de São Sebastião. $\mathrm{O}$ objetivo do artigo foi delinear como ocorreu a transição histórica do porto natural ao porto organizado. O objetivo justifica-se em razão da centralidade das atividades portuárias na história do município. A presença das condições físicas apropriadas ao funcionamento do porto refletiram-se na inserção histórica e econômica de São Sebastião.

Denota-se que a ocupação do núcleo original do município remete ao aproveitamento das condições naturais para a instalação do porto. Durante todo o período colonial, o porto de São Sebastião contribui para a relevância econômica e comercial do município. É possível afirmar que São Sebastião, naquele período, apresentava relevância regional em razão das atividades relacionadas ao porto. Entretanto, fazse necessário observar o impacto do deslocamento espacial e temporal do capital. No século XIX, o crescimento das atividades relacionadas à expansão da cafeicultura implicou na superação do porto local. O porto de Santos tornou-se o fator de articulação entre os centros de consumo externos e o café brasileiro. E a dificuldade de efetivar processos de modernização logística, necessária à recuperação do protagonismo do porto de São Sebastião, definiu as condições naturais, sem a realização de 
investimentos no sistema de transporte e operação portuária, como insuficientes para a preservação de uma condição relevante.

A industrialização brasileira no século XX favoreceu a modernização do porto de São Sebastião. A passagem do porto natural para o porto organizado ocorreu sob a necessidade de locais com condições adequadas à operação da Petrobras, completando o processo de modernização iniciado ainda na década de 1930. De fato, as condições naturais desempenharam papel decisivo para a instalação da Petrobras no município. Mas foram necessários investimentos para o aproveitamento dessas características. A transição do porto natural para o porto organizado destaca como as mudanças regionais e locais estão condicionadas a condições endógenas e exógenas.

A industrialização brasileira com a consequente necessidade de investimentos em infraestrutura de logística e atividades econômicas adequadas ao suporte do crescimento econômico provocou o deslocamento espacial do capital, transformador da realidade de São Sebastião. E a presença de condições naturais que originaram o porto favoreceram a execução das ações de modernização relacionadas às atuais condições do município, do que se depreende que a transição do porto natural ao porto organizado delineia a história do município e caracteriza suas condições de desenvolvimento.

\section{Referências}

AESP. Arquivo do Estado de São Paulo. Documentos interessantes para a história e costumes de São Paulo. São Paulo, Casa Eclética, v. 1-92, 1894-1978. Acervo consultado em setembro de 2015.

ALMEIDA, A. P. D. Memória Histórica sobre São Sebastião. Sociedade de Estudos Históricos de São Paulo, São Paulo, p. 232, 1959.

ANTAQ. Agência Nacional de Transportes Aquaviária. Portal Antaq, 2010. Disponível em: <http://www.antaq.gov.br/Portal/Estatisticas_Anuarios.asp>. Acesso em: 5 setembro 2015.

BRASIL. Decreto no 983, de 8 de agosto de 1892. República dos Estados Unidos do Brazil. Capital Federal, 1892.

. Decreto no 50.555, de 5 de maio de 1961. Brasília, 1961.

. Lei no 8.630, de 25 de fevereiro de 1993. Disponível em:

<http://www.planalto.gov.br/ccivil_03/leis//8630.htm.1993>. Acesso em: 4 abr. 2014.

. Lei no 12.815, de 5 de junho de 2013. Congresso Nacional. Brasília, 2013.

. Mensagem lida perante a Assembléia Nacional Constituinte, no ato da sua instalação. Acervo da biblioteca da Presidência da República. Disponível em: <http://www.biblioteca.presidencia.gov.br/presidencia/ex-presidentes/getuliovargas/discursos/1933/09.2.pdf/view>. Acesso em: 20 set. 2015.

CANO, W. Desequilíbrios regionais e concentração industrial no Brasil - 1930-1970. Campinas: UNESP, 2007. 
CDSS. Porto de São Sebastião. Localização e Características. Porto de São Sebastião, 2013. Disponível em: <http://www.portodesaosebastiao.com.br/pt-br/arquivos/ pdf/Localizacao-e-caracteristicas.pdf>. Acesso em: 20 jan. 2014.

CHRISTOPHER, M. Logística e gerenciamento da cadeia de suprimentos: criando redes que agregam valor. Tradução de Mauro de Campos SILVA. 2. ed. São Paulo: Thomson Learning, 2007.

CORRÊA DA SILVA, A. O litoral norte do Estado de São Paulo: formação de uma região periférica. São Paulo: USP, 1975.

CUNHA, Í. Conflito ambiental em águas costeiras: Relação porto-cidade no Canal de São Sebastião. Ambiente \& Sociedade, São Paulo, v. VI, n. 2, p. 83-98, jul./dez. 2003.

DOU. Diário Oficial da União de 04/05/1925. Disponível em: <https://www.jusbrasil. com.br/diarios/DOU/1925/05/04>. Acesso em: 5 nov. 2015.

FRANCISCO, J.; CARVALHO, P. D. F. Desconstrução do Lugar: o aterro da praia da frente do centro histórico de São Sebastião (SP). Lucia Helena de Oliveira Ambientes. Estudos de Geografia, Rio Claro, v. 1, p. 105-119, 2003.

FURTADO, C. Formação econômica do Brasil. 34. ed. São Paulo: Companhia das Letras, 2007.

GIANESELLA, R. Gêneses urbanas do colonialismo: síntese de encontros culturais. Anais do Museu Paulista. São Paulo: USP, 2012. p. 165-200.

HARVEY, D. A produção capitalista do espaço. São Paulo: Annablume, 2006.

IBGE. Instituto Brasileiro de Geografia e Estatística. Estatísticas do Século XX. 2013. Disponível em: <http://seculoxx.ibge.gov.br/en/populacionais-sociais-politicas-eculturais/busca-por-temas/populacao>. Acesso em: 5 set. 2016.

KAPPEL, R. F. et al. Os Portos Brasileiros novo desafio para a sociedade.

III Conferência Nacional de C T\&I, Brasília, Centro de Gestão e Estudos Estratégicos, p. 1-31, 2005.

LUNA, V.; COSTA, I. D. N. Posse de escravos em São Paulo no início do século XIX. São Paulo: IPE, 1983.

MONIÉ, F.; VIDAL, S. M. S. C. Cidades, portos e cidades portuárias na era da integração produtiva. RAP, Rio de Janeiro, v. 40, n. 6, p. 975-995, 2006.

NOTTEBOOM, T. E.; RODRIGUE, J. P. Port regionalization: towards a new phase in port development. MaritimePolicy\& Management, London, v. 32, n. 3, p. 297-313, July-September 2005.

POCHMANN, M. O emprego no desenvolvimento da nação. São Paulo: Boitempo, 2015.

PORTO, M. M.; TEIXEIRA, S. G. Portos e meio ambiente. São Paulo: Aduaneiras, 2001. 
REIS, H. A relação porto-cidade em São Sebastião no contexto da sua evolução histórico-espacial. Revista Geográfica de América Central: XIII Encuentro de Geógrafos de América Latina (Versión Electrónica), Heredia, 2, n. 47E, 1-18, 2011.

RESSURREIÇÃO, R. D. D. São Sebastião: transformações de um povo caiçara. São Paulo: Humanitas, 2002.

RODRIGUE, J. P. Chapter 5 - International Trade and Freight Distribution. In: RODRIGUE, J. P.; COMTOIS, C.; SLACK, B. The Geography of Transport Systems. v. 3. 3. ed. New York: Routledge, 2013.

RODRIGUES, E. W. Porto de São Sebastião e o desenvolvimento local: influências das atividades portuárias. Taubaté: Universidade de Taubaté, 2015.

RODRIGUES, E. W.; SANTOS, M. J. Infraestrutura dos portos brasileiros: análise do impacto da atuação das empresas transnacionais. 20 APDR Congress Renaissance of the Regions of Southern Europe. Évora: University of Évora, 2014.

RODRIGUES, I. D. O.; SANTOS, J. D.; OLIVEIRA, T. M. R. D. Médio Vale do Paraíba Sul: Estado, Políticas Públicas e Organização do Espaço 1930/1980. Revista Brasileira de Geografia, Rio de Janeiro, p. 57-82, out./dez. 1992.

SÃO PAULO. Decreto 22.518 - Regulamento do Porto de São Sebastião. Governo do Estado de São Paulo. São Paulo, 1953. . Lei no 1.776. Governo do Estado de São Paulo. São Paulo, 1952.

SANTOS, M. A natureza do espaço: Técnica e tempo, razão e emoção. 4. ed. São Paulo: USP, 2006.

. Pensando o espaço do homem. 5. ed. São Paulo: USP, 2009.

SANTOS, E. L. et al. Desenvolvimento: um conceito multidimensional. DRD - Desenvolvimento Regional em Debate, Canoinhas, ano 2, n. 1, p. 44-61, 2012.

SEP/PR. Secretaria de Portos da Presidência da República. Nota à Imprensa. Publicado em 3 dez. 2012. Disponível em: <http://www.portosdobrasil.gov.br/ home-1/noticias/2012/nota-a-imprensa-sep-pr>. Acesso em: 20 ago. 2014.

SINGER, P. Urbanização e Desenvolvimento o caso São Paulo. In: SINGER, P. Economia Política da Urbanização. São Paulo: CEBRAP, 1975. p. 115-133. 